\title{
Quinpirole and $d$-amphetamine administration posttraining enhances memory on spatial and cued discriminations in a water maze
}

\author{
MARK G. PACKARD and JAMES L. MCGAUGH \\ University of California, Irvine, California
}

\begin{abstract}
Two behavioral testing procedures, a spatial discrimination and a cued discrimination, were used in a water maze to assess memory enhancement following posttraining administration of $d$-amphetamine, an indirect catecholamine agonist, and quinpirole, a dopaminergic D2 receptor agonist. Rats received an eight-trial (30-sec intertrial interval) training session on a single-platform spatial or cued discrimination in a water maze. In the spatial task, a submerged escape platform was located in the same quadrant of the maze on all trials. In the cued task, a visible escape platform was located in a different quadrant of the maze on each trial. Following Trial 8 in both tasks, the rats received a posttraining subcutaneous injection of $d$-amphetamine (1.0 $\mathrm{mg} / \mathrm{kg})$, quinpirole (LY $171555 ; 2.0 \mathrm{mg} / \mathrm{kg}$ ), or saline. On a retention test session $24 \mathrm{~h}$ later, latency to mount the escape platform was used as a measure of memory. In both tasks, the retention test escape latencies of the animals given $d$-amphetamine or quinpirole were lower than those of the salineinjected controls. In both tasks, injections of $d$-amphetamine and quinpirole did not affect retention when administered $2 \mathrm{~h}$ posttraining, indicating a time-dependent effect of the posttraining treatments on retention. Control experiments indicated that the effects of $d$-amphetamine on retention were not due to enhancement of memory of a "search strategy" common to both tasks. Rather, the effects of the drug on retention were due to an influence on memory for the "type" of discrimination learned (i.e., spatial or cued). The findings indicate that both spatial and cued discriminations in a water maze are sensitive to posttraining memory enhancement, and they suggest a neuromodulatory role for dopaminergic systems in both tasks.
\end{abstract}

Studies using posttraining treatments have contributed significantly to our understanding of the neuroanatomical and neurochemical systems involved in memory. Early clinical as well as experimental findings (Breen \& McGaugh, 1961; Burnham, 1904; Duncan, 1949; Zubin \& Barrera, 1941) supported the view that immediately following a training experience, memory is in a labile state, and over time the information is "consolidated" into a more permanent state (Hebb, 1949; Muller \& Pilzecker, 1900). An important feature of posttraining treatments is that their effects are time dependent: They are most effective when administered shortly after training. Such effects are consistent with consolidation theory and, in addition, indicate that the effects of posttraining treatments on subsequent retention performance are not due to a proactive action on motivational, sensory, or motoric processes (McGaugh, 1966, 1973, 1989).

Posttraining administration of $d$-amphetamine, an indirect catecholamine agonist, and quinpirole, a dopaminergic D2 receptor agonist, enhances memory on both appetitively (Krivanek \& McGaugh, 1969; Oscos, Mar-

This research was supported by National Research Service Award 1 F32 NS08973-01 from NINDS to M.G.P., and by USPHS Grant MH12526 from NIMH and NIDA to J.L.M. Address correspondence to M. G. Packard, Department of Psychology, University of New Orleans, Lakefront, New Orleans, LA 70148 tinez, \& McGaugh, 1988; Packard \& White, 1989, 1991; Strupp, Bunsey, Levitsky, \& Kesler, 1991) and aversively (Castellano, Cestari, Cabib, \& Pulglisi-Allegra, 1991; Doty \& Doty, 1966; Evangelista \& Izquierdo, 1971; Gasbarri, Introini-Collison, Packard, Pacitti, \& McGaugh, 1993; Martinez et al., 1980; Viaud \& White, 1989; White \& Viaud, 1991) motivated learning tasks.

Using two behavioral testing procedures, a spatial discrimination and a cued discrimination in a water maze, we further examined the memory-enhancing properties of posttraining administration of $d$-amphetamine and quinpirole. The spatial discrimination task requires animals to learn to swim to a hidden escape platform that is positioned in the same spatial location on every trial. The cued discrimination task requires animals to learn to swim to a visibly cued escape platform that is positioned in a different spatial location on every trial. These tasks provide an interesting assessment in view of findings indicating that damage to the hippocampal system impairs acquisition of spatial, but not cued, discriminations in a water maze (Morris, Garrud, Rawlins, \& O’Keefe, 1982; Sutherland, Kolb, \& Whishaw, 1982; Sutherland, Whishaw, \& Kolb, 1983) and that, in contrast, damage to the caudate nucleus impairs acquisition of a twoplatform cued, but not spatial, discrimination in a water maze (Packard \& McGaugh, 1992). Thus, if retention in these two tasks is sensitive to posttraining manipulations, 
they may prove useful for examining the neurochemical bases of different forms of memory.

\section{EXPERIMENT 1}

In Experiment 1 animals received a single, eight-trial training session on either the spatial or cued discriminations and a posttraining systemic injection of saline, $d$ amphetamine, or quinpirole.

\section{Method}

Subjects. The subjects were 110 male Sprague-Dawley rats (275-300 g; Charles River). They were individually housed in a temperature-controlled environment on a 12:12-h light:dark cycle with the lights on from 7 a.m. to 7 p.m. The rats had ad-lib access to food and water. Behavioral testing occurred between 1 p.m. and 4 p.m.

Apparatus. The water maze was a black, circular galvanized steel tank, $1.83 \mathrm{~m}$ in diameter and $0.58 \mathrm{~m}$ in height. The tank was filled with water $\left(25^{\circ} \mathrm{C}\right)$ to a depth of $20 \mathrm{~cm}$. The maze was located in a room containing many extramaze cues. Four starting positions (north, south, east, west) were equally spaced around the perimeter of the tank, dividing the pool into four equal quadrants. The rectangular Plexiglas escape platform $(11 \times 14 \times 19 \mathrm{~cm})$ was submerged at a depth of $1 \mathrm{~cm}$. For the cued water maze task, a white rubber ball $(8 \mathrm{~cm}$ in diameter) was attached to the top of the submerged platform and protruded above the water surface. The platform could be used as a step to mount the ball and escape the water.

Drugs. The drugs $d$-amphetamine (Sigma Co.) and quinpirole (LY 171555; Research Biochemicals, Inc.) were dissolved in physiological saline. Injections were administered subcutaneously on the dorsal surface of the neck. Injection volume was $1 \mathrm{ml} / \mathrm{kg}$. Control animals were injected with saline.

Behavioral procedures. In both the spatial and cued tasks, the animals received one training session of eight trials (i.e., swims). The animal was placed into the tank facing the wall at one of the four designated start points (N, S, E, or W) and allowed to escape onto the hidden or cued platform. A different starting point was used on each trial so that each starting point was used twice within the eight trials. If an animal did not escape within $60 \mathrm{sec}$, it was manually guided to the escape platform. After mounting the platform, the rats remained on the platform for $20 \mathrm{sec}$. Following each trial they were removed from the maze and placed into a holding cage for a $30-\mathrm{sec}$ intertrial interval. The latency to mount the escape platform was recorded and used as a measure of acquisition of each task.

In the spatial discrimination task, the hidden escape platform was located in the same quadrant on every trial. In the cued discrimination task, the escape platform was placed in a different quadrant on each trial so that each of the four quadrants contained the escape platform on two of the eight trials. The locations of the start points for the cued task were arranged so that distance to the escape platform (i.e., proximal or distal) and location of the platform relative to the start point (i.e., left or right) were counterbalanced across the eight trials.

Immediately following the last training trial, the animals were randomly assigned to treatment groups (spatial discrimination task: $d$-amphetamine $1 \mathrm{mg} / \mathrm{kg}, n=14$, quinpirole $2 \mathrm{mg} / \mathrm{kg}, n=8$, saline, $n=11$; cued discrimination task: $d$-amphetamine $1 \mathrm{mg} / \mathrm{kg}$, $n=13$, quinpirole $2 \mathrm{mg} / \mathrm{kg}, n=7$, saline, $n=11$ ) and received a posttraining subcutaneous injection of either drug or vehicle. The $d$-amphetamine- and saline-treated animals were run in two replications, which accounts for the higher number of animals in these two groups. The drug doses were chosen on the basis of previous findings demonstrating their effectiveness in enhancing memory in other learning tasks when administered posttraining (Oscos et al.,
1988; Packard \& White, 1989; Packard, Williams, \& McGaugh, 1992). Additional groups of animals received identical training, but were injected with $d$-amphetamine $(n=6)$ or quinpirole $(n=6)$ $2 \mathrm{~h}$ after training.

Retention was tested $24 \mathrm{~h}$ after completion of the training. The retention test on the spatial task consisted of two trials. The submerged escape platform was located in the same quadrant of the maze as during training. On each of these two trials, a different starting point that was located distal to the escape platform was used. The retention test on the cued task consisted of four trials. As during training, the visible escape platform was placed in a different quadrant of the maze on each trial. On each of these four trials, a different start point that was located distal to the visible escape platform was used. In both tasks the latency to mount the escape platform was recorded for all retention test trials and used as a measure of memory for the previous day's training session.

Statistical analyses. Two-way analyses of variance (ANOVAs) with one repeated measure were used to assess the statistical significance of group differences over the training and retention test trials. Tests of simple main effects (group within trial) and Newman-Keuls post hoc analyses were used to determine specific group differences.

\section{Results}

Spatial discrimination task: $d$-amphetamine. A twoway one-repeated-measure ANOVA computed on the escape latencies on the training day revealed no significant group differences $[F(2,28)=.09$, n.s. $]$. A significant trial effect $[F(2,7)=34.5, p<.01]$ indicated that all the groups improved over the eight training trials, obtaining mean escape latencies of $15-20 \mathrm{sec}$ on Trials 7-8.

The effect of posttraining administration of $d$-amphetamine on retention in the spatial discrimination task is shown in Figure 1a. The retention test escape latencies of the $d$-amphetamine group were significantly lower than those of the saline and $d$-amphetamine/delay groups on Trial 1 [group effect for Trial $1, F(2,28)=6.15, p<$ .01 ; Newman-Keuls post hoc test for $d$-amphetamine and saline, $Q>4.40$ ]. On retention test Trial 2, there were no significant group differences, although a trend toward significance was observed $[F(2,28)=3.11, p<.06]$.

Spatial discrimination task: quinpirole. A two-way one-repeated-measure ANOVA computed on the escape latencies on the training day revealed no significant group differences $[F(2,22)=.63$, n.s. $]$. A significant trial effect $[F(2,7)=25.2, p<.01]$ indicated that all the groups improved over the eight training trials, obtaining mean escape latencies of 15-20 sec on Trials 7-8.

The effect of posttraining injection of quinpirole on retention in the spatial discrimination task is shown in Figure $1 \mathrm{~b}$. The retention test escape latencies of the quinpirole group were significantly lower than those of the saline and quinpirole/delay groups on Trial 1 [group effect for Trial $1, F(2,22)=3.57, p<.05$; NewmanKeuls post hoc test for quinpirole and saline, $Q>3.62$ ]. There were no significant differences in escape latencies among the groups on the second retention test trial $[F(2,22)=1.45$, n.s. $]$.

Cued discrimination task: $d$-amphetamine. A twoway one-repeated-measure ANOVA computed on the escape latencies on the training day revealed no significant group differences $[F(2,27)=.86$, n.s. $]$. A significant trial 
effect $[F(2,7)=84.1, p<.01]$ indicated that all the groups improved over the eight training trials, obtaining mean escape latencies of 10-15 sec on Trials 7-8.

The effect of posttraining administration of $d$-amphetamine on retention in the cued discrimination task is shown in Figure 2a. The retention test escape latencies of the $d$-amphetamine group were significantly lower than those of the saline and $d$-amphetamine/delay groups on Trials 1 , 2 , and 3 [group effect for all trials and each individual trial, $F_{\mathrm{s}}(2,27)>3.41, p<.05$; Newman-Keuls post hoc test for $d$-amphetamine and saline, $Q>3.43$ ].

Cued discrimination task: quinpirole. A two-way one-repeated-measure ANOVA computed on the escape latencies on the training day revealed no significant group differences $[F(2,21)=0.5$, n.s. $]$. A significant trial effect $[F(2,7)=57.5, p<.01]$ indicated that all the groups improved over the eight training trials, obtaining mean escape latencies of $10-15 \mathrm{sec}$ on Trials 7-8.

The effect of posttraining injection of quinpirole on retention in the cued discrimination task is shown in Fig-
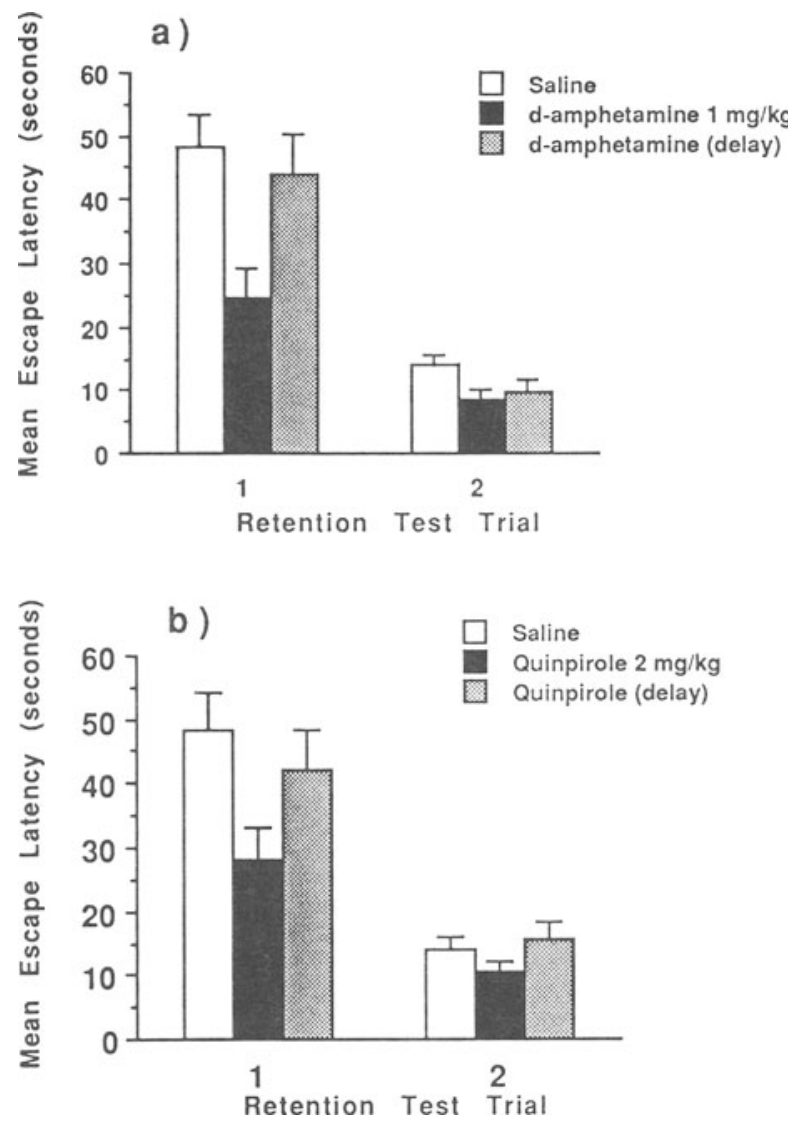

Figure 1. Mean $( \pm S E)$ escape latencies of $d$-amphetamine and saline-treated rats on the two retention test trials in the spatial discrimination; the $d$-amphetamine/delay group received injections $(2 \mathrm{~h})$ posttraining (a). Mean ( $\pm S E$ ) escape latencies of quinpirole- and saline-treated rats on the two retention test trials in the spatial discrimination; the quinpirole/delay group received injections $(2 \mathrm{~h})$ posttraining (b).
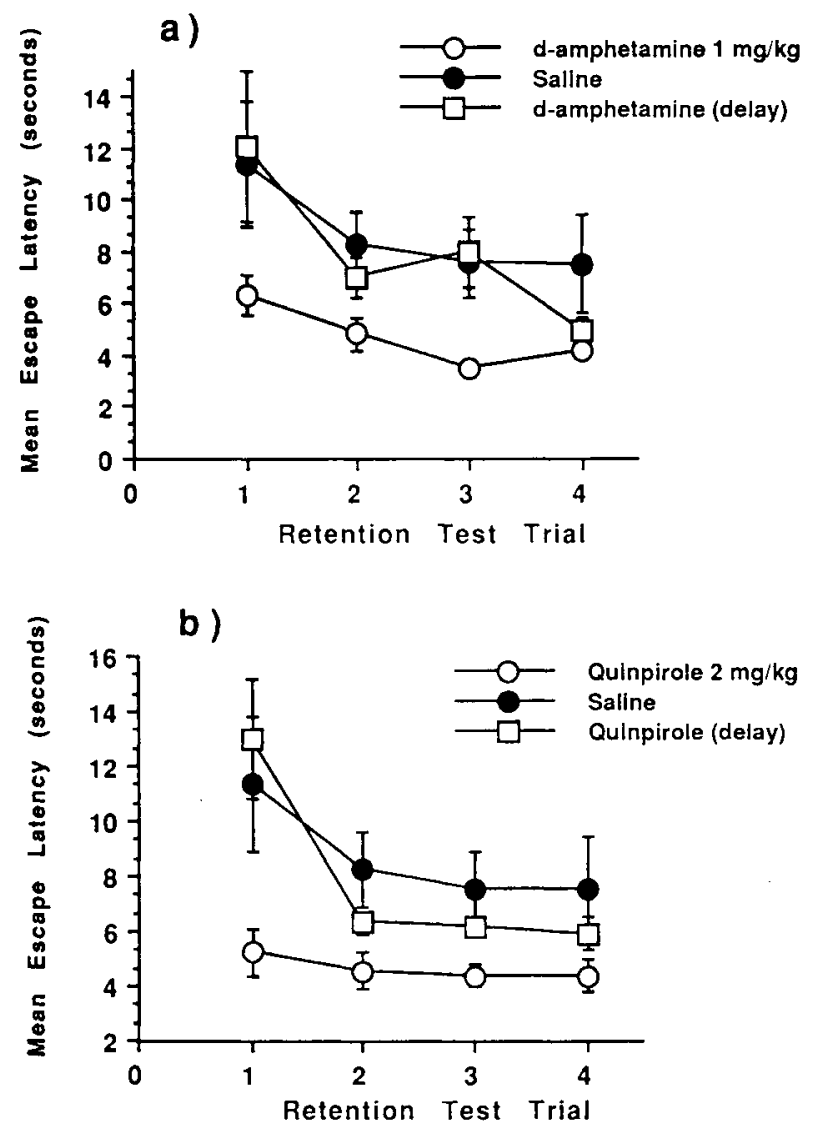

Figure 2. Mean $( \pm S E)$ escape latencies of $d$-amphetamine and saline-treated rats on the four retention test trials in the cued discrimination; the $d$-amphetamine/delay group received injections $(2 \mathrm{~h})$ posttraining (a). Mean $( \pm S E)$ escape latencies of quinpirole- and saline-treated rats on the four retention test trials in the cued discrimination; the quinpirole/delay group received injections $(2 \mathrm{~h})$ posttraining (b).

ure $2 b$. The retention test escape latencies of the quinpirole group were significantly lower than those of the saline and quinpirole/delay groups on Trials 1 and 2 [group effect for all trials and each individual trial, $F_{\mathrm{s}}(2,21)>3.32, p<.05$; Newman-Keuls post hoc test for quinpirole and saline, $Q>3.55$ ].

\section{EXPERIMENT 2}

The findings of Experiment 1 indicate that posttraining administration of $d$-amphetamine and quinpirole enhances memory in a time-dependent manner in both spatial and cued discriminations in a water maze. Although the findings suggest that both tasks are sensitive to posttraining memory enhancement, they do not unequivocally demonstrate that the drugs enhanced memory for the "type" of discrimination (i.e., spatial or cued) used. The observed enhancement of retention performance may have been due to an effect of the drugs on memory for a gen- 


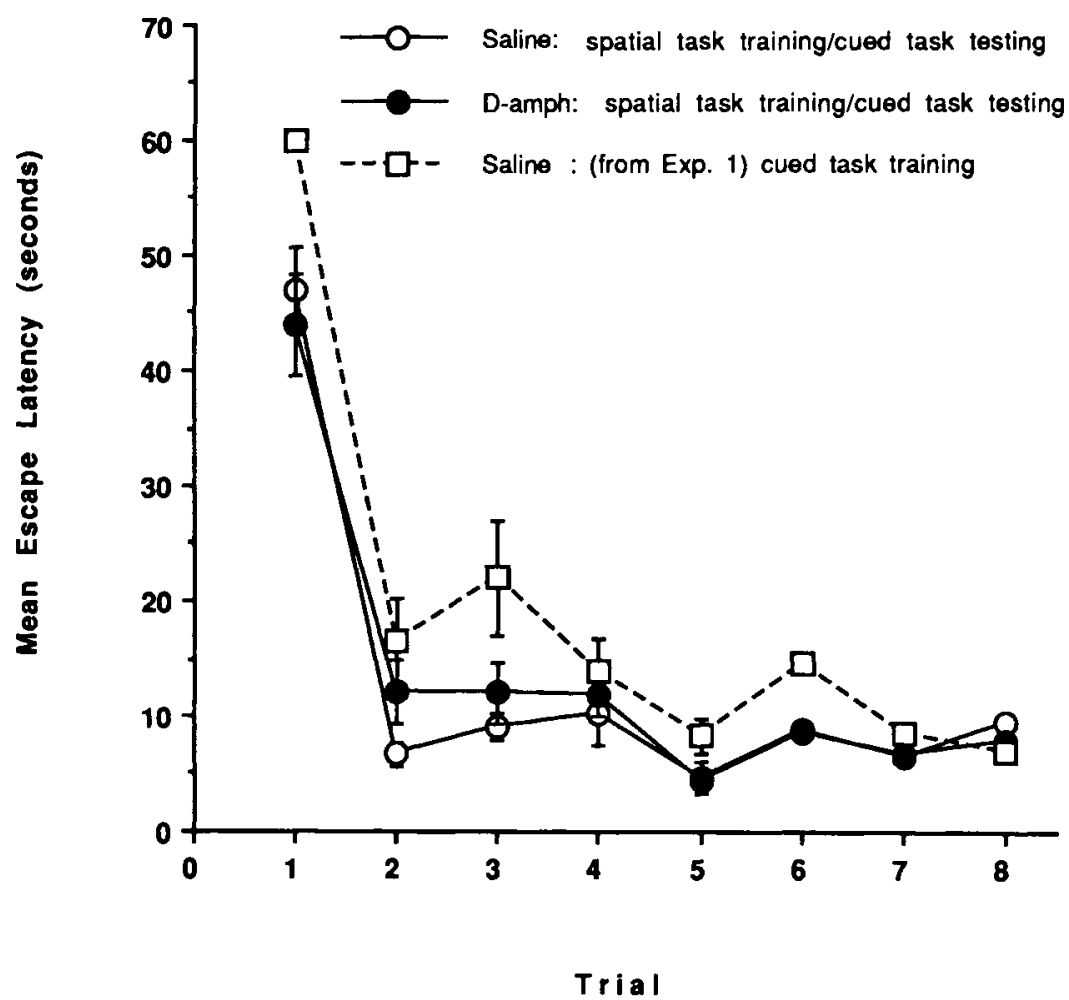

Figure 3. Mean escape latencies of the saline and $d$-amphetamine animals initially trained on the spatial discrimination and tested on the cued discrimination (solid lines). Broken line illustrates the training day escape latencies of saline-treated animals that received training only on the cued discrimination (data from Experiment 1).

eral "search strategy" common to both tasks. For example, in both tasks the escape platform was located in a position that was the same distance from the pool wall, although in the spatial task this position was constant on each trial and in the cued task this position was changed on each trial. Nonetheless, in either task the drugs may have enhanced memory for a strategy such as "search $\mathrm{X}$ distance from the pool wall." To examine this possibility in Experiment 2, animals received training on either the spatial or cued discrimination task, followed by posttraining administration of $d$-amphetamine or saline. On a retention test session, the animals trained in the cued task were tested in the spatial task, and those trained in the spatial task were tested in the cued task. If the retention-enhancing effects of $d$-amphetamine observed in Experiment 1 were due to an influence on memory for a search strategy common to both tasks, then such enhancement should be observed regardless of the type of discrimination training (i.e., spatial or cued) that was originally received. Alternatively, if the retentionenhancing effects of $d$-amphetamine were due to an influence on memory for the type of discrimination training received, then such enhancement should not be observed if the animals are tested on the task that is opposite to the one that they had originally received training on.

\section{Method}

Subjects. The subjects were 24 male Sprague-Dawley rats (275-300 g), housed in conditions identical to those of Experiment 1 .

Apparatus. The apparatus was the same as that of Experiment 1.

Drugs. The drug $d$-amphetamine (Sigma Co.) was dissolved in physiological saline. Drug administration was identical to that of Experiment 1.

Behavioral procedure. The training and retention test procedures were similar to those described for Experiment 1 . Immediately following an eight-trial training session in either the spatial or cued discrimination tasks, the rats received a posttraining injection of either $d$-amphetamine $(1.0 \mathrm{mg} / \mathrm{kg}$ ) or saline ( $n=6$ per group). Twenty-four hours later, the animals trained in the spatial discrimination were given an eight-trial retention test in the cued discrimination. The animals trained in the cued discrimination were given an eight-trial retention test in the spatial discrimination.

\section{Results}

The retention test escape latencies of the saline and $d$ amphetamine animals trained on the spatial discrimination and tested on the cued discrimination are shown in Figure 3 (solid lines). The retention test escape latencies of the saline and $d$-amphetamine animals trained on the cued discrimination and tested on the spatial discrimination are shown in Figure 4 (solid lines). Two-way one-repeatedmeasure ANOVAs revealed no significant group differ- 
ences between saline- and $d$-amphetamine-treated animals in either condition [Figure $3, F(1,10)=.55$, n.s.; Figure $4, F(1,10)=.67$, n.s.], indicating that the memory enhancement produced by posttraining $d$-amphetamine on both discrimination tasks (Experiment 1) was not observed when the animals were tested in tasks that were different from those in which they had received original training.

The training day escape latencies of the saline animals from Experiment 1 that were trained in the cued and spatial discriminations are also shown in Figures 3 and 4, respectively (broken lines). Comparison of the performance of these groups with that of the animals tested in the task that was different from that in which they were originally trained shows that the latter animals received little (albeit some) benefit from a single, eight-trial training session in either task. A one-way ANOVA computed on Trial 1 (Figure 3), which included the training day escape latencies of the animals trained in the spatial task in addition to the test day latencies of the animals trained and tested in different tasks, revealed no significant group differences $[F(2,20)=.61$, n.s.]. In contrast, a one-way ANOVA computed on Trial 1 (Figure 4), which included the training day escape latencies of the animals trained in the cued task in addition to the test day latencies of those trained and tested in different tasks, did reveal a significant group difference $[F(2,20)=11.68, p<.01]$. However, post hoc analyses revealed that both the saline$(Q>4.11)$ and $d$-amphetamine-treated $(Q>3.67)$ animals trained in the spatial task and tested in the cued task escaped faster on Trial 1 than the animals trained in the cued task (Figure 4). Moreover, the magnitude of this effect was not as large as that produced by $d$-amphetamine when the animals were trained and tested on the cued task (mean test day escape latency on Trial 1 for $d$-amphetamine animals trained and tested in the cued task $=6.32 \mathrm{sec}$; mean test day escape latency on Trial 1 for $d$-amphetamine animals trained on the spatial task and tested in the cued task $=43.83 \mathrm{sec}$ ). Taken together, these findings suggest that acquisition of the two tasks proceeds somewhat independently, despite the fact that they share some characteristics, such as swimming away from the pool wall.

\section{DISCUSSION}

These findings indicate that posttraining administration of $d$-amphetamine, an indirect catecholamine agonist, and quinpirole, a dopaminergic D2 receptor agonist, enhances memory in both spatial and cued discriminations in a water maze. It is important to note that in each task the memoryenhancing effects of both drugs were time dependent, in-

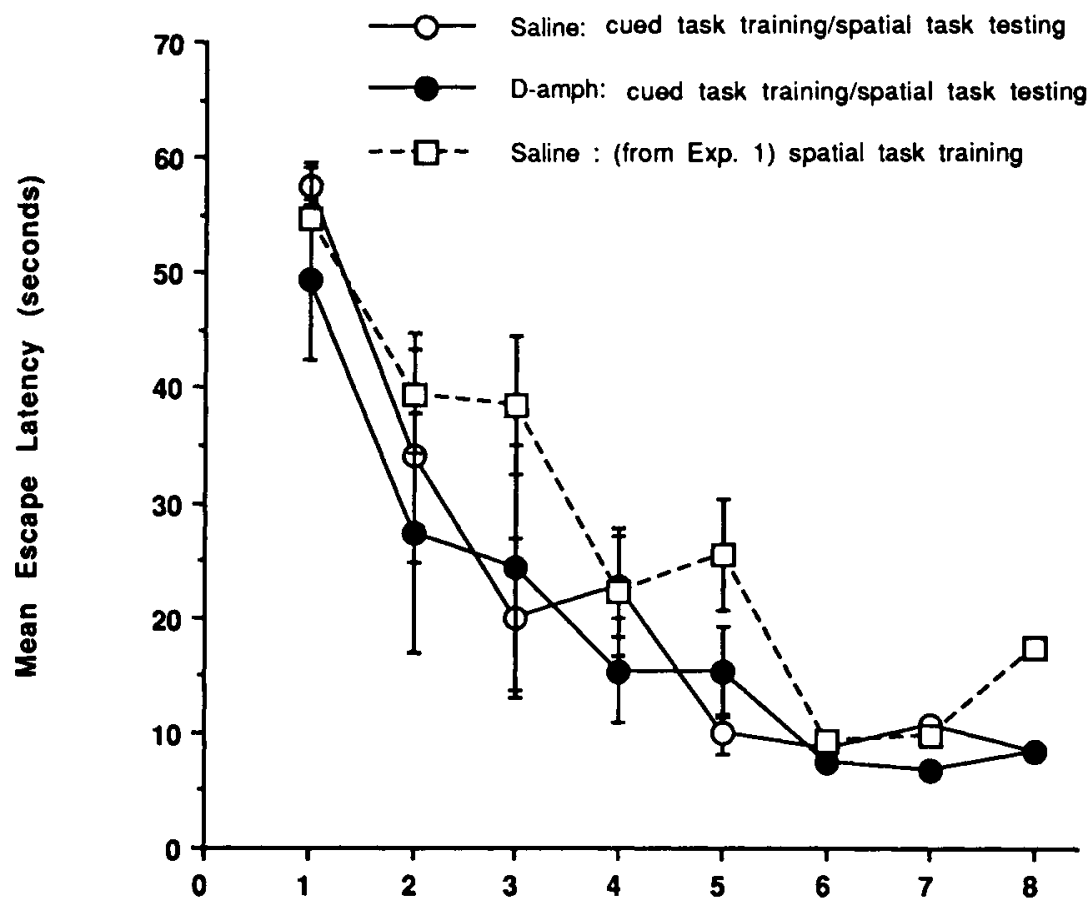

Trial

Figure 4. Mean escape latencies of the saline and $d$-amphetamine animals initially trained on the cued discrimination and tested on the spatial discrimination (solid lines). Broken line illustrates the training day escape latencies of saline-treated animals that received training only on the spatial discrimination (data from Experiment 1). 
dicating that the effects were not due to a proactive action of the drugs on retention performance (McGaugh, 1966, 1973, 1989). The findings of Experiment 1 are consistent with those of other studies reporting that memory is enhanced by posttraining injections of $d$-amphetamine (Doty \& Doty, 1966; Krivanek \& McGaugh, 1969; Martinez et al., 1980; Oscos et al., 1988; Packard \& White, 1989; Strupp et al., 1991) and quinpirole (Castellano et al., 1991; Gasbarri et al., 1993; Packard \& White, 1989, 1991; White \& Viaud, 1991).

As an indirect catecholamine agonist, $d$-amphetamine releases both dopamine and norepinephrine (Weiner, 1980 ). Evidence suggests that memory enhancement produced by $d$-amphetamine is mediated through influences on dopamine: 6-hydroxydopamine lesions of the nigrostriatal dopamine system block the memory-enhancing effects of peripheral posttraining administration of $d$ amphetamine in a conditioned emotional response task (White, 1988), and administration of the dopaminergic antagonist haloperidol, but not the noradrenergic antagonist propranolol, blocks the memory-enhancing effects of $d$-amphetamine on retention in a win-shift radial maze task (Williams, Packard, \& McGaugh, in press).

In Experiment 2 the retention-enhancing effects of $d$ amphetamine were not observed when the animals were tested in a discrimination task that was different from the one in which they were originally trained. These findings indicate that the effects of $d$-amphetamine observed in Experiment 1 were not due to an influence of the drug on memory for a general search strategy common to both tasks. Rather, the findings indicate that the enhancement was due to an influence on memory for the specific discrimination (i.e., spatial or cued) learned.

There is extensive evidence suggesting that brain systems mediating memory vary with the learning task used to assess memory (e.g., McDonald \& White, 1993; Packard, Hirsh, \& White, 1989; Packard \& White, 1991; ZolaMorgan, Squire, \& Mishkin, 1982). Acquisition of twoplatform (Morris, 1984) versions of the spatial and cued water maze discrimination tasks, which are similar to the single-platform versions used in the present study, appear to be mediated by different brain systems. Lesions of the hippocampal system impair acquisition of spatial but not cued discriminations, and lesions of the caudate nucleus impair acquisition of cued but not spatial discriminations (Packard \& McGaugh, 1992). Furthermore, while peripheral administration of both $d$-amphetamine and quinpirole enhanced retention in both spatial and cued discriminations in a radial maze (Packard \& White, 1989), the effects of posttraining intracerebral injections of these drugs were site specific. Intrahippocampal, but not intracaudate, injections of $d$-amphetamine and quinpirole selectively enhanced acquisition of a spatial task (Packard \& White, 1991). In contrast, intracaudate, but not intrahippocampal, injections of $d$-amphetamine and quinpirole selectively enhanced acquisition of a cued task (Packard \& White, 1991). Thus, it would be of interest to conduct experiments using injections into specific brain regions to determine whether the memory-enhancing effects of $d$-amphetamine and quinpirole seen in the present experiments involved an action on the hippocampal system in the spatial discrimination task and on the caudate nucleus in the cued discrimination task. As both the spatial and cued discriminations in the water maze are sensitive to posttraining drug enhancement, these tasks should prove useful for examining brain systems mediating neuromodulatory influences on different forms of memory.

\section{REFERENCES}

Breen, R. A., \& McGaugh, J. L. (1961). Facilitation of maze learning with posttrial injections of picrotoxin. Journal of Comparative \& Physiological Psychology, 54, 495-501.

BuRnham, W. H. (1904). Retroactive amnesia: Illustrative cases and a tentative explanation. American Journal of Psychology, 14, 382-396.

Castellano, C., Cestari, V., Cabib, S., \& Pulglisi-Allegra, S. (1991). Post-training dopamine receptor agonists and antagonists affect memory storage irrespective of their selectivity for D1 and D2 receptors. Behavioral \& Neural Biology, 56, 283-291.

DotY, B., \& DotY, L. A. (1966). Facilitative effects of amphetamine on avoidance conditioning in relation to age and problem difficulty. Psychopharmacologia, 9, 234-241.

DunCan, C. P. (1949). The retroactive effect of electroshock on learning. Journal of Comparative \& Physiological Psychology, 42, 32-44.

Evangelista, A. M., \& IZquierdo, L. (1971). The effect of pre- and post-trial amphetamie injections on avoidance responses in the rat. Psychopharmacologia, 20, 42-47.

Gasbarri, A., Introini-Collison, I. B., Packard, M. G., Pacitti, C., \& MCGAUGH, J. L. (1993). Interaction of cholinergic-dopaminergic systems in the regulation of memory storage in aversively motivated learning tasks. Brain Research, 627, 72-78.

HeBB, D. O. (1949). The organization of behavior. New York: Wiley. KrivaneK, J., \& McGaugh, J. L. (1969). Facilitating effects of preand post-training amphetamine administration on discrimination learning in mice. Agents \& Actions, 1, 36-42.

Martinez, J. L., Jensen, R. A., Messing, R. B., Vasquez, B. J., Soumireu-Mourat, B., Geddes, G., Liang, K. C., \& McGaugh, J. L. (1980). Central and peripheral actions of amphetamine on memory storage. Brain Research, 182, 157-166.

MCDONALD, R. J., \& WhITE, N. M. (1993). Triple dissociation of memory systems: Hippocampus, amygdala, and dorsal striatum. Behavioral Neuroscience, 107, 3-22.

McGaugh, J. L. (1966). Time-dependent processes in memory storage. Science, 153, 1351-1358.

MCGAUGH, J. L. (1973). Drug facilitation of learning and memory. Annual Review of Pharmacology, 13, 229-240.

McGaugh, J. L. (1989). Dissociating learning and performance: Drug and hormone enhancement of memory storage. Brain Research Bulletin, 23, 339-345.

MoRRIs, R. G. M. (1984). Development of a water-maze procedure for studying spatial representation in the rat. Journal of Neuroscience Methods, 11, 47-60.

Morris, R. G. M., Garrud, P., Rawlins, J. N. P., \& O'Keefe, J. (1982). Place navigation impaired in rats with hippocampal lesions. Nature, 297, 681-683.

Müller, G. E., \& Pilzecker, A. (1900). Experimentelle Beiträge zur Lehre von Gedächtnis. Zeitschrift für Psychologie (Suppl. 1)

Oscos, A., Martinez, J. L., \& McGaugh, J. L. (1988). Effects of post-training $d$-amphetamine on acquisition of an appetitive autoshaped lever press response in rats. Psychopharmacology, 95, 132-134.

Packard, M. G., Hirsh, R., \& White, N. M. (1989). Differential effects of fornix and caudate nucleus lesions on the acquisition of two radial maze tasks: Evidence for multiple memory systems. Journal of Neuroscience, 9, 1465-1472. 
Packard, M. G., \& McGaugh, J. L. (1992). Double dissociation of fornix and caudate nucleus lesions on acquisition of two water maze tasks: Further evidence for multiple memory systems. Behavioral Neuroscience, 106, 439-446.

Packard, M. G., W Wite, N. M. (1989). Memory facilitation produced by dopamine agonists: Role of receptor subtype and mnemonic requirements. Pharmacology, Biochemistry \& Behavior, 33, 511-518.

PACKARD, M. G., \& WHITE, N. M. (1991). Dissociation of hippocampus and caudate nucleus memory systems by post-training intracerebral injection of dopamine agonists. Behavioral Neuroscience, 105, 295-306.

Packard, M. G., Williams, C. L., \& McGaugh, J. L. (1992). Enhancement of win-shift radial maze retention by peripheral posttraining administration of $d$-amphetamine and 4-OH amphetamine. Psychobiology, 20, 280-285.

Strupp, B. J., Bunsey, M., Levitsky, D., \& Kesler, M. (1991). Timedependent effects of post-trial amphetamine treatment in rats: Evidence for enhanced storage of representational memory. Behavioral \& Neural Biology, 56, 62-76.

Sutherland, R. J., KolB, B., \& Whishaw, I. Q. (1982). Spatial mapping: Definitive disruption by hippocampal or medial frontal cortex damage in the rat. Neuroscience Letters, 31, 271-276.

Sutherland, R. J., WhishaW, I. Q., \& KolB, B. (1983). A behavioral analysis of spatial localization following electrolytic, kainate- or colchicine-induced damage to the hippocampal formation in rats. $B e$ havioral Brain Research, 7, 133-153.

ViaUd, M. D., \& WhITE, N. M. (1989). Dissociation of visual and olfactory conditioning in the neostriatum of rats. Behavioral Brain Research, 32, 31-42.

WEINER, N. (1980). Norepinephrine, epinephrine, and the sympathomimetic amines. In A. Goodman Gilman, L. S. Goodman, \& A. Gilman (Eds.), The pharmacological basis of therapeutics (pp. 138-176). New York: MacMillan.

White, N. M. (1988). Effect of nigrostriatal dopamine depletion on the post-training, memory improving action of amphetamine. Life Sciences, 43, 7-12.

WhITE, N. M., \& VIAUD, M. D. (1991). Localized intracaudate dopamine D2 receptor activation during the post-training period improves memory for visual or olfactory conditioned emotional responses in rats. Behavioral \& Neural Biology, 55, 255-269.

Williams, C. L., Packard, M. G., \& McGaugh, J. L. (in press). Amphetamine facilitation of win-shift radial-arm maze retention: The involvement of peripheral adrenergic and central dopaminergic systems. Psychobiology.

Zola-Morgan, S., Squire, L., \& Mishkin, M. (1982). The neuroanatomy of amnesia: Amygdala-hippocampus versus temporal stem. Science, 218, 1337-1339.

ZUBIN, J., \& BARRERA, S. E. (1941). Effect of electric convulsive therapy on memory. Proceedings of the Society of Experimental \& Biological Medicine, 48, 596-597.

(Manuscript received May 3, 1993;

revision accepted for publication October 25,1993 .) 